\title{
STATE OF THE ART OF SURFACE TEXTURING FOR BIOTRIBOLOGY APPLICATIONS
}

\author{
Daniel I. Quintanilla-Correa ${ }^{1}$, Laura Peña-Parás ${ }^{1}$, Demofilo Maldonado-Cortés ${ }^{1}$, Martha \\ Claudia Rodriguez-Villalobos ${ }^{2}$, Marco A. L. Hernández-Rodríguez ${ }^{3}$ \\ ${ }^{1}$ Universidad de Monterrey, Engineering Department, Ave. I. Morones Prieto 42550 Pte. C.P. 66230, San Pedro Garza \\ García, Nuevo León, México \\ ${ }^{2}$ Universidad de Monterrey, Physics and Mathematics Department, Ave. I. Morones Prieto 42550 Pte. C.P. 66230, San \\ Pedro Garza García, Nuevo León, México \\ ${ }^{3}$ Universidad Autónoma de Nuevo León, Facultad de Ingeniería Mecánica y Eléctrica, Av. Universidad S/N, C.P. 66450, \\ San Nicolas de los Garza, Nuevo León, México \\ Corresponding author: Laura Pena-Paras, laura.pena@udem.edu
}

\begin{abstract}
Surface texturing can be defined as a technique that consists of creating micro cavities in the surface of a material. There are different texturing techniques such as chemical etching, electromechanical micromachining, diamond embossing, electric discharge, pellet-pressing and laser surface, the last being the most common. For years, these surface texturing techniques have been used in tribological applications because microcavities can store oils or fluids and constantly lubricate the surfaces that are subjected to wear; they can also be used to trap wear particles (debris) that would otherwise act as abrasive particles (three body abrasive wear). This literature review seeks to analyse and compare the advantages that the use of surface texturing techniques can offer in reducing the wear of prosthetic components and therefore lengthening their useful life, to provide a better quality of life to patients. The results of this review showed a growing interest in the scientific community in the use of surface texturing for biotribogical applications, using to a greater extent the Laser Surface Texturing (LST) technique and the surface pattern composed by dimples.
\end{abstract}

Key words: surface texturing, biomedical applications, prosthesis, lubrication, COF, cavities, tribology, wear.

\section{INTRODUCTION}

For years, efforts have been made to enhance the useful life of tools, pieces, and devices in different industries, and biomedicine is not the exception. The main problem of joint prostheses is their short useful life of approximately 15 years [1,2], after this period patients need to undergo to a revision surgery where one or more components of the implant must be replaced. In some cases, the revision surgeries are caused by the constant fatigue to which the prostheses are subjected, which can even cause a fracture of the implant; likewise, the wear of materials can also produce the deterioration of the implant components.
The constant friction between the components of the prosthesis tends to manifest in the form of wear particles, the size of these can vary, depending mainly on the constituent materials of the implant. With the use of a Scanning Electron Microscope (SEM) for the characterization of different implant samples, it has been shown that the average size of the wear particles is $0.5 \mu \mathrm{m}$; furthermore, it is ensured that almost $90 \%$ of them are smaller than 1 $\mu \mathrm{m}$. Like the size of the wear particles, the materials used for the manufacture of each prosthesis can vary, these two factors are very important to determine the type of response the tissues will produce; for example, titanium particles generally do not affect cell viability [3]. On the other hand, there is evidence that the wear particles of a CobaltChromium (CoCr) alloy can cause hypersensitivity of the hip, due to the inflammation of the tissues adjacent to the prosthesis [4]. Over time, the use of the metal-on-metal friction couple has been reduced, since there is evidence that it tends to produce ions and particles that can cause diseases in the body $[5,6]$. The generation of metallic particles tends to be characterized by producing a very aggressive reaction; however, even though polyethylene debris generate a lower response than metallic particles, the contribution to the general biological response in vivo is usually greater than that of metallic particles, since the polymeric ones are produced to a greater extent [3]. In addition to this, the production of Ultra High Molecular Weight Polyethylene (UHMWPE) wear particles can cause implant loosening in the medium and long term, which translates into a surgical reintervention [7].

In some cases, the enhancement in useful life has been obtained with the development of new 
materials; however, for biomedical applications the formulation of new materials is supervised by strict regulations, since both the chemical composition and the mechanical properties of the biomaterials must have certain specifications to avoid secondary effects. That is why the interest arises to extend the useful life of materials without altering their chemical composition. An effective alternative is the use of surface engineering techniques, such as Coatings, Thermochemical Treatments, or Surface Texturing. Surface Texturing is a technique that is defined as a selective material removal process, where micro or nano cavities are created on the surface of a material. There are different texturing techniques such as

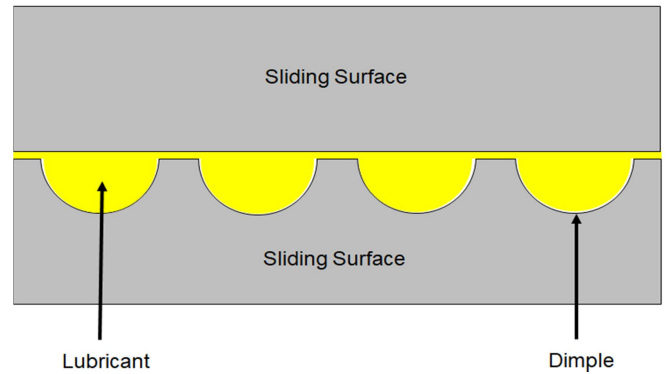

(a) sandblasting, ion beam texturing, etching technique, machining, and laser texturing, being the last one the most innovative in recent years $[8,9]$.

Surface texturing has been used successfully in tribological applications where it is sought to reduce wear between sliding surfaces, since there is evidence that the cavities that are created with this technique can be used to store lubricant (Figure 1(a)) and keep the sliding surfaces constantly lubricated; furthermore, the cavities can also be used to trap wear particles (debris) that would otherwise produce third-body abrasive wear [9-12], as can be seen in Figure 1(b).

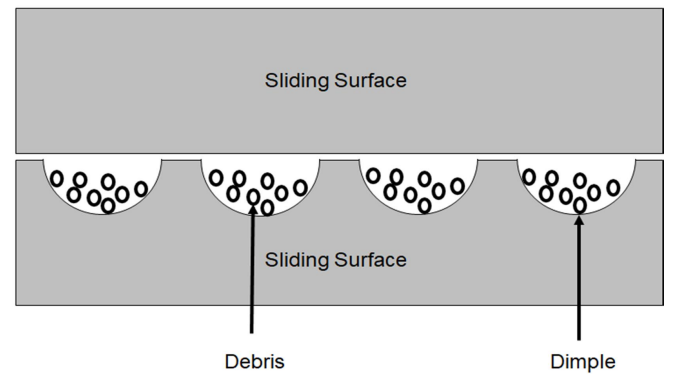

(b)

Fig. 1. Schematic representation of the tribological effect of surface texturing: a) Storage of lubricant; b) Debris trapped inside the cavities

In some cases, the benefits of texturing have been used for biotribological applications with the aim of reducing wear between components of joint prostheses, where positive results have been obtained; an example of this is the work of Ito et al., where concave dimples (diameter of $0.5 \mathrm{~mm}$, pitch of 1.2 $\mathrm{mm}$, and depth of $0.1 \mathrm{~mm}$ ) were textured on the surface of a Co-Cr alloy femoral head using the electrical discharge etching technique. Wear tests were carried out using a hip joint simulator with a metal-on-polyethylene configuration, the results showed that dimples reduced COF and wear by $35 \%$ and $68 \%$, respectively [13]. Another example is the work of Sawano et al., where CoCrMo alloy plates were textured with dimples using an abrasive waterjet and then tested using a pin-on-plate tribotester with UHMWPE pins to simulate a joint prosthesis. The results showed a wear reduction of $0.2 \mathrm{mg}$ in UHMWPE when $1 \mu \mathrm{m}$ deep dimples were textured in the sliding surface of the CoCrMo plates. The reduction in wear is attributed to the fact that dimples acted as micro traps for the wear particles. With their findings, the authors suggest that the useful life of joint prostheses can be increased to approximately 33 years if the proposed micro-dimple in metal surfaces are used [2].

In this review, a comparison will be made of some of the most important surface texturing techniques used in biomedical applications, especially in those whose reduce the friction and wear on materials used for the manufacture of joint prostheses.

\section{SURFACE TEXTURING TECHNIQUES}

As can be seen in Figure 2, Surface Texturing research has risen in recent years, reaching up to 2400 publications in 2020, according to scientific search engine "sciencedirect.com" and keyword surface texturing for biomedical applications. A trend and a clear increase in the number of published works can be shown over the 15 years, which can be translated into an interest of the scientific community in exploring the effect that surface texturing has in biotribology applications.

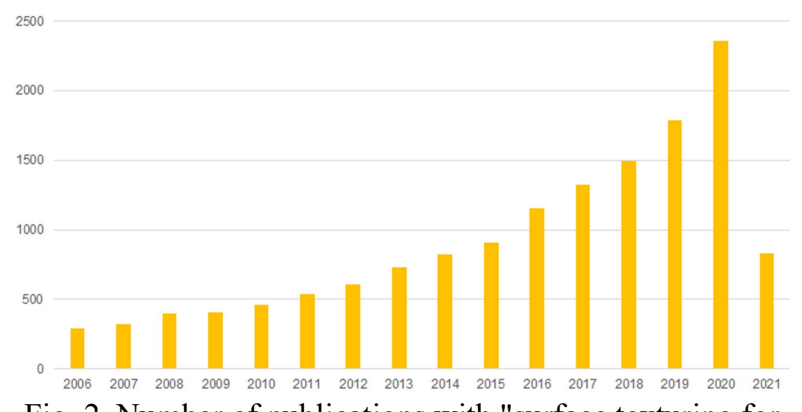

Fig. 2. Number of publications with "surface texturing for biomedical applications" as search topic, according to Sciencedirect.com 
As mentioned above, there are different surface texturing techniques, each with different advantages and disadvantages; likewise, different parameters can be manipulated in each one to produce the cavities, in this section some of the most popular techniques will be described.

The complexity of the surface texturing techniques can vary, there are investigations where different techniques are combined to obtain a texturing pattern, such as the work of Zhang et al., where samples of SS316 and UHMWPE were textured using combinations of lithography-electrolytic etching and lithography-moulding, respectively. In the case of the SS316, a photo-resist mask was manufactured according to a standard lithography process using a spin-coater, then the pattern was transferred to the surface of the sample using an electrolytic etching technique, finally a solvent was used to remove the photo-resist mask. On the other hand, for the UHMWPE texturing the photo-resist mask was coated on the surface of a copper mould according to a standard lithography process, then UHMWPE powder was emptied inside a hot-press mould with the copper mould and pressed with $48 \mathrm{MPa}$ at $200{ }^{\circ} \mathrm{C}$ for $90 \mathrm{~min}$, the last step is the mould remotion after being cooled to room temperature [14].

Laser surface texturing (LST) is a technique used to modify the surface and, in some cases, the chemical composition of some materials. The operating principle of the LST is based on focusing a direct laser beam to the surface of a material, after the laser radiation is absorbed by the outermost layer, the optical energy from the laser produces an increase in the temperature of the material, reaching to reach vaporization temperatures and may even melt a portion of the surface. The modification of the chemical composition can occur when the photons of the laser beam have enough energy to break the chemical bonds of the material [15]. This highly adaptable technique uses a computer-controlled laser to generate cavities on the surface of a material, some of the parameters that can be manipulated for the generation of these cavities are the dimensions of the geometry, laser power, frequency, pulse duration and scanning speed [16,17]. There is a variant of the LST, named Masked Laser Surface Texturing (MLST), where a mask is placed and fixed on top of the surface of the material to be textured, the mask acts as a filter preventing the passage of a portion of the laser beam on the sample, in order to draw the texturized patterns [18]. Figure 3 shows a schematic representation of the MLST operating principle.
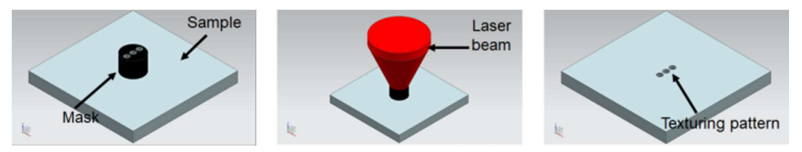

Fig. 3. Schematic representation of MLST

There are different machining surface texturing techniques, for example, some authors such as Dong et al., use mechanical indenter machines (Rockwell roller indenter) for the fabrication of cavities [19], in other cases a micromachining centre is used for the machining texturing, like the work of Pratap, et al., where a Mikrotools DT-110 was used for microdimpled generation in Ti6Al4V samples. In this investigation different machining tools were used to obtain different geometries such as micro flat-end mill, micro ball-end mill, and micro drill. The spindle speed and feed were set to $60000 \mathrm{rpm}$ and $120 \mathrm{~mm} / \mathrm{min}$, respectively, to minimize the cutting forces exerted in the surface of the material where the dimples were generated [20]. In some cases, a diamond drill bit is used in order to reduce the possibility of forming wear debris in the micromachining process [21]. It is important to mention that if a strict control in the manipulation of the machining input parameters to generate texturing cavities is obtained, it is possible to even machine ceramic samples, proof of this is the investigation of Roy, et al., where a CNC micro machine (Mikrotools DT110) with a solid carbide drill bit (400 $\mu \mathrm{m}$ diameter) was used to fabricate microdimples in $\mathrm{Al}_{2} \mathrm{O}_{3}$ samples, the spindle speed and feed rate were maintained at 55,000 rpm and $334 \mathrm{~mm} / \mathrm{min}$, respectively [22]. Table 1 shows a comparison of the input parameters of LST and Machining Surface Texturing used in different biotribology publications.

Table 1. Surface texturing techniques and parameters

\begin{tabular}{|c|c|c|c|c|c|c|c|c|c|}
\hline $\begin{array}{l}\text { Texturing } \\
\text { technique }\end{array}$ & $\begin{array}{l}\text { Textured } \\
\text { material }\end{array}$ & $\begin{array}{l}\text { Wavelength } \\
{[\mathrm{nm}]}\end{array}$ & $\begin{array}{c}\text { Power } \\
{[\mathrm{W}]}\end{array}$ & $\begin{array}{c}\text { Scanning } \\
\text { speed } \\
{[\mathrm{mm} / \mathrm{s}]}\end{array}$ & $\begin{array}{c}\text { Frequency } \\
{[\mathrm{Hz}]}\end{array}$ & $\begin{array}{c}\text { Pulse } \\
\text { duration } \\
\text { [ns] }\end{array}$ & $\begin{array}{c}\text { Spindle } \\
\text { speed } \\
{[\mathrm{rpm}]}\end{array}$ & $\begin{array}{l}\text { Feed rate } \\
{[\mathrm{mm} / \mathrm{min}]}\end{array}$ & Ref. \\
\hline LST & $\mathrm{Al}_{2} \mathrm{O}_{3} / \mathrm{TiC}$ & 1064 & 16.2 & 5 & 6000 & 10 & NA & NA & [23] \\
\hline LST & $\mathrm{Al}_{2} \mathrm{O}_{3} / \mathrm{TiC}$ & 1064 & - & 5 & 6000 & 10 & NA & NA & [24] \\
\hline LST & $\mathrm{CoCr}$ & 1064 & 6000 & 2 & 4.5 & $7 \mathrm{e}+6$ & NA & NA & [16] \\
\hline LST & CoCrMo & 532 & 0.05 & - & 100000 & 0.01 & NA & NA & [12] \\
\hline LST & CoCrMo & 1064 & 20 & $50-200$ & $3000-5500$ & - & NA & NA & [25] \\
\hline LST & PEEK & 1064 & 10 & 5 & 10000 & 4 & NA & NA & [26] \\
\hline LST & PEEK & 1030 & 0.22 & - & 50000 & $4 \mathrm{e}-4$ & NA & NA & [27] \\
\hline LST & Ti6Al4V & 1064 & 1.2 & 400 & 20000 & 35 & NA & NA & [28] \\
\hline LST & Ti6Al4V & 610 & 70 & $0.5-10$ & 60 & - & NA & NA & [29] \\
\hline LST & Ti6Al4V & 1064 & - & 5 & 2000 & 20 & NA & NA & {$[30]$} \\
\hline LST & Ti6Al4V & 1064 & 10 & 5 & 10000 & - & NA & NA & {$[8,31]$} \\
\hline LST & Ti6Al4V & - & 21 & 1 & 5000 & - & NA & NA & [32] \\
\hline
\end{tabular}




\begin{tabular}{|c|l|l|l|l|l|l|l|l|l|}
\hline LST & Ti6A14V & 193 & - & - & 200 & 5 & NA & NA & {$[10]$} \\
\hline LST & Ti6A14V & 1060 & 9.1 & - & 100000 & 26 & NA & NA & {$[33]$} \\
\hline LST & Ti6A14V & 355 & 5 & $500-1500$ & 30000 & - & NA & NA & {$[34]$} \\
\hline LST & Ti6A14V & 1064 & 10 & 5 & 10000 & - & NA & NA & {$[35]$} \\
\hline LST & Ti6A14V & 800 & 0.1 & 1 & 1000 & $3.5 \mathrm{e}-5$ & NA & NA & {$[36]$} \\
\hline LST & Ti6A14V & 1064 & - & - & - & 450 & NA & NA & {$[37]$} \\
\hline LST & Ti6A14V & 1064 & - & 1.2 & 10000 & 0.01 & NA & NA & {$[38]$} \\
\hline LST & UHMWPE & 1024 & - & $25-40$ & $20 \mathrm{e}+6-30 \mathrm{e}+6$ & - & NA & NA & {$[39]$} \\
\hline MLST & Ti6A14V & 1064 & - & 20 & - & 10 & NA & NA & {$[40]$} \\
\hline Machining & $\mathrm{Al}_{2} \mathrm{O}_{3}$ & NA & NA & NA & NA & NA & 55000 & 334 & {$[22,41]$} \\
\hline Machining & Ti6A14V & NA & NA & NA & NA & NA & 60000 & 120 & {$[20,42]$} \\
\hline
\end{tabular}

\section{GEOMETRIES OF SURFACE TEXTURING}

Just as there are different texturing techniques, there are also different geometries that can be implemented to generate texturing patterns. Some commonly used geometries are dimples, triangles, squares, diamonds; in other cases, linear grooves, wavy grooves, crosshatch are also used. In Figure 4, an illustration of some of the most common texturing patterns used is presented.
Figure 5 shows a pie chart where the most used texturing patterns in the publications consulted in this review are illustrated. There is a clear trend in the use of Dimples, Crosshatch and Lines with $51 \%, 16 \%$ and $14 \%$, respectively. The preference for the use of dimples can be attributed to the fact that it is a relatively easy geometry to texturize, in addition to this, dimple textures have proven to be effective in tribological applications, reaching COF reductions of up to $80 \%$ compared to non-textured sliding surfaces [8].
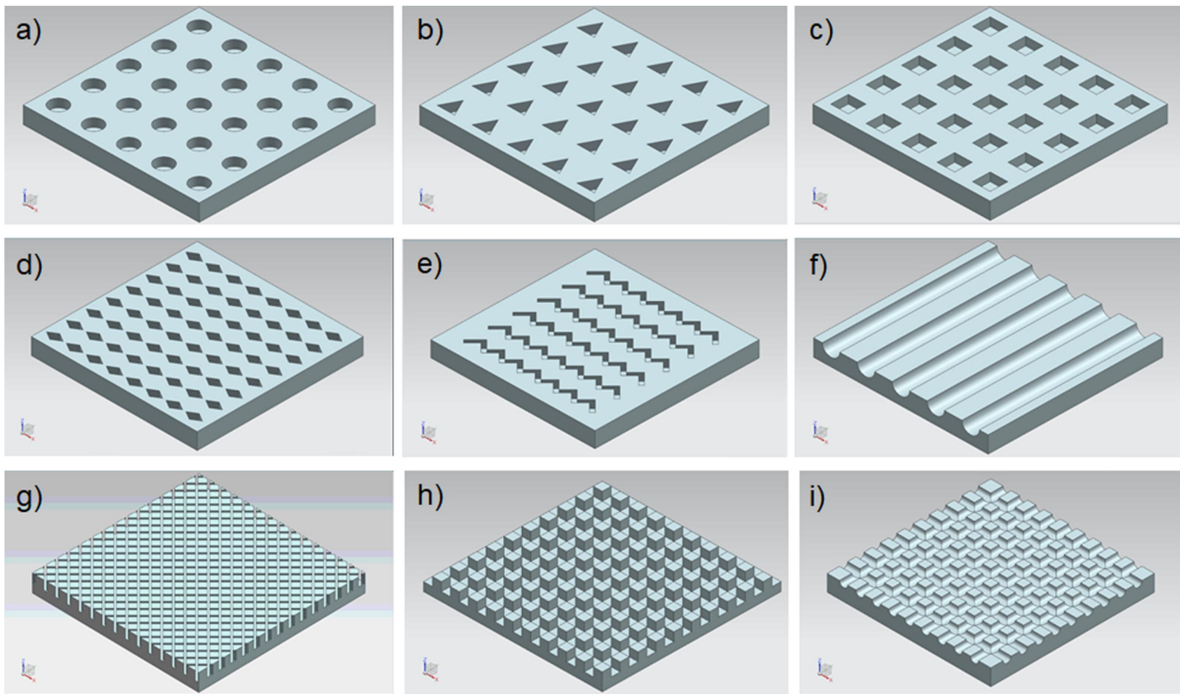

Fig. 4. Surface texturing patterns. a) Dimple; b) Triangle; c) Square; d) Diamond; e) Wavy groove; f) Linear groove; g) Diamond crosshatch; h) and i) Square crosshatch

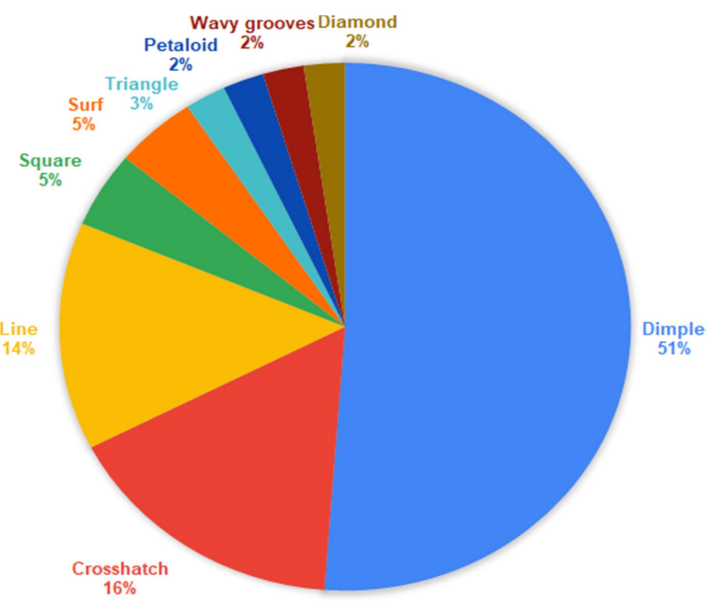

Fig. 5. Surface texturing patterns pie chart 
Some of the most important characteristics of the geometries are the texture density, which can be defined as the portion of the surface that the cavities occupy, some authors affirm that the optimum density for tribology applications is $16 \%$ [17].

Table 2. Surface texturing geometries

\begin{tabular}{|c|c|c|c|c|c|c|c|c|}
\hline Geometry & $\begin{array}{l}\text { Textured } \\
\text { material }\end{array}$ & Bearing & $\begin{array}{l}\text { Density } \\
(\%)\end{array}$ & $\begin{array}{l}\text { Cavity } \\
\text { length } \\
(\mu \mathrm{m})\end{array}$ & $\begin{array}{l}\text { Cavity } \\
\text { depth } \\
(\mu \mathrm{m})\end{array}$ & $\begin{array}{l}\text { Distance } \\
\text { between } \\
\text { cavities } \\
(\mu \mathrm{m})\end{array}$ & $\begin{array}{l}\mathrm{COF} \\
\text { reduction } \\
(\%) *\end{array}$ & Ref. \\
\hline Crosshatch & UHMWPE & Ceramic & $43.4-51$ & $500-600$ & $110-120$ & $650-850$ & 53.47 & [39] \\
\hline Crosshatch & UHMWPE & $\mathrm{Si}_{3} \mathrm{~N}_{4}$ & - & - & 1 & - & 40 & [43] \\
\hline Crosshatch & Ti6A14V & Bovine bone & - & $40-140$ & $15.2-49$ & $0-100$ & -83.33 & [28] \\
\hline Crosshatch & Ti6Al4V & UHMWPE & $9.75-10.38$ & $50-200$ & 10 & $853-2458$ & 13.51 & {$[36]$} \\
\hline Cross groove & Ti6Al4V & Ti6Al4V & $18-64$ & 43 & 4.5 & $171-378$ & 79.56 & [38] \\
\hline Diamond, Dimple & CoCrMo & UHMWPE & $37-58$ & $55-190$ & $1.5-9.5$ & $80-500$ & 45 & [19] \\
\hline Dimple & $\mathrm{Al}_{2} \mathrm{O}_{3}$ & $\mathrm{Al}_{2} \mathrm{O}_{3}$ & $5.84-9.78$ & 400 & 20 & $1500-2000$ & 15.15 & [22] \\
\hline Dimple & $\mathrm{Al}_{2} \mathrm{O}_{3}$ & $\mathrm{Al}_{2} \mathrm{O}_{3}$ & 15 & $300-400$ & 30 & $400-1800$ & 23.03 & [41] \\
\hline Dimple & $\mathrm{CCM}+$ & $\mathrm{CCM}+$ & - & $80-100$ & 6-10 & 250 & 4.28 & [44] \\
\hline $\begin{array}{l}\text { Dimple, Line, Net, } \\
\text { Surf }\end{array}$ & $\mathrm{CoCr}$ & $\mathrm{Al}_{2} \mathrm{O}_{3}$ & $\begin{array}{l}9.86- \\
100\end{array}$ & 450 & $\begin{array}{l}40.8- \\
235.9\end{array}$ & $\begin{array}{l}1000- \\
1300\end{array}$ & 40 & [16] \\
\hline $\begin{array}{l}\text { Dimple, triangle, } \\
\text { square }\end{array}$ & CoCrMo & Ti6Al4V & - & $50-150$ & $8-16$ & $100-300$ & 20.51 & {$[25]$} \\
\hline Dimple & PEEK & SS316L & $15-30$ & 300 & 100 & - & 3.22 & [26] \\
\hline Dimple & PEEK & $\mathrm{Al}_{2} \mathrm{O}_{3}$ & $10-48$ & 30 & $2-21$ & 79-156 & 27.58 & [27] \\
\hline Dimple & SS316 & UHMWPE & $5-40$ & 50 & 15 & - & 66.66 & [14] \\
\hline Dimple & Ti6Al4V & Zirconium & $6.5-42.6$ & $186-267$ & $3-6.2$ & $120-600$ & 27.05 & [29] \\
\hline Dimple & Ti6Al4V & GCr15 steel & - & 70 & 50 & 200 & 41.39 & {$[30]$} \\
\hline Dimple & Ti6Al4V & AISI 52100 & $28-44$ & $45-300$ & 25 & 100 & 79.82 & {$[8]$} \\
\hline Dimple & Ti6Al4V & AISI 52100 & $13-44$ & 150 & 40 & - & 64.46 & [31] \\
\hline Dimple & Ti6Al4V & GCr15 steel & - & 450 & 13 & - & 36.61 & [40] \\
\hline Dimple & Ti6Al4V & AISI 52100 & 44 & 36 & 25 & 52 & 15.73 & [35] \\
\hline Dimple & Ti6Al4V & GCr15 steel & 21.20 & 260 & - & 500 & -8.96 & [37] \\
\hline Dimple & Ti6Al4V & Ti6Al4V & 16.20 & 410 & 30 & 950 & 31.89 & [21] \\
\hline Dimple & Ti6Al4V & Ti6Al4V & - & $\begin{array}{l}122.66- \\
410\end{array}$ & $19.61-30$ & $298.76-950$ & 22.41 & [20] \\
\hline Dimple, Linear & Ti6Al4V & $\begin{array}{l}\text { AISI E-52100 } \\
\text { steel }\end{array}$ & - & $25-60$ & - & 20 & 54.13 & {$[10]$} \\
\hline Linear groove & $\mathrm{Al}_{2} \mathrm{O}_{3}$ & AISI 1045 steel & - & $40-50$ & $40-50$ & $150-250$ & 78.08 & [24] \\
\hline $\begin{array}{l}\text { Linear groove, Wavy } \\
\text { groove }\end{array}$ & $\mathrm{Al}_{2} \mathrm{O}_{3} / \mathrm{TiC}$ & $\begin{array}{l}\text { AISI } 1045 \\
\text { steel }\end{array}$ & - & $40-50$ & $40-50$ & $100-250$ & -5.16 & [23] \\
\hline Linear channel & Ti6Al4V & 100 Cr6 steel & - & 30 & 10 & - & 23.07 & [33] \\
\hline Microgroove & Ti6Al4V & $\mathrm{Si}_{3} \mathrm{~N}_{4}$ & - & $25-65$ & $10.4-12.3$ & 100 & 71.15 & [34] \\
\hline $\begin{array}{l}\text { Parallel micro-dimpled, } \\
\text { Stagered micro- } \\
\text { dimpled, Micro grid }\end{array}$ & Ti6Al4V & Ti6Al4V & - & $87-142$ & $20-30$ & 200 & 34.44 & [42] \\
\hline Petaloid & CoCrMo & CoCrMo & 44.1 & 90 & 5 & 150 & 30.04 & [12] \\
\hline Square & Ti6Al4V & - & $72-81$ & $30-150$ & $71.15-87.15$ & - & 81.39 & [32] \\
\hline
\end{tabular}

Other characteristics that are commonly modified are the length and depth of the cavities, since as mentioned previously the cavities can be used to store lubricant and debris. Table 2 presents a comparison of different geometries, specifying their characteristics (density, length, depth) and the difference in COF obtained when using these patterns in different tribology tests (pin on disc, ball on disc, ring on disc, etc.) in comparison to non-textured surfaces.

\section{DISCUSSION}

In general, the use of mesh-shaped texturing patterns has proven to have favourable results in tribological tests, different works where UHMWPE and Ti6Al4V samples were textured with crosshatch patterns and subjected to wear against sliding surfaces (UHMWPE, Ti6Al4V, $\mathrm{Si}_{3} \mathrm{~N}_{4}$ ) obtained $\mathrm{COF}$ reductions in the range of $13-80 \%[36,38,39,43]$. On the other hand, in the work of Tiainen et al., crosshatch arrays were textured on Ti6Al4V samples and then tribological tested against bovine bone plates. The results were not as expected, since an increase in COF was observed in the textured samples compared to grift-blasted surfaces. The authors attribute this phenomenon to the fact that the bone debris adhered to the Ti6Al4V surface creating a layer, so the COF was not measured between the 
bone and the metallic surface but between compacted bone and bone bulk [28].

The use of ceramic materials for the manufacture of joint prostheses has been of great importance in recent years, since it has been shown that prostheses composed of a ceramic-on-ceramic friction pair present a considerably lower wear rate, compared to prostheses with metal-on-metal, metal-on-polymer and ceramic-on-polymer bearings [45]. With the implementation of surface texturing, the wear rate of ceramic-on-ceramic bearings can be further reduced, as in Roy et al., investigations, where $\mathrm{Al}_{2} \mathrm{O}_{3}$ discs were textured with dimple arrays, then pin-on-disc tests were carried out using $\mathrm{Al}_{2} \mathrm{O}_{3}$ pins. A $15 \% \mathrm{COF}$ reduction was achieved using a micro-dimple array with density of $9.78 \%$, diameter and dept of $400 \mu \mathrm{m}$ and $20 \mu \mathrm{m}$, respectively [22]. On the other hand, when the dimple array had a density of $15 \%(400 \mu \mathrm{m}$ diameter and $20 \mu \mathrm{m}$ depth), the COF difference raised up to $23 \%$ [41]. In both cases, the textured samples were compared to untextured $\mathrm{Al}_{2} \mathrm{O}_{3}$ discs with the same testing conditions. Similarly, in the work by Xing et al., $\mathrm{Al}_{2} \mathrm{O}_{3} / \mathrm{TiC}$ samples with linear grooves were textured, with length and depth of 40$50 \mathrm{um}$ and then a $\mathrm{WS}_{2} / \mathrm{Zr}$ coating was added. The samples were subjected to ball on disc tests using AISI 1045 steel ball as bearing, in the results a COF reduction of $78 \%$ was reached [24].

As mentioned above, the use of dimples as texturing patterns is widely used with the aim of reducing wear in biotribology applications. These circles can be fabricated using different texturing techniques varying the characteristics of the cavities, obtaining positive results as in the investigations of Zhang et al., and $\mathrm{Hu}$ et al., where dimpled textured SS316 (diameter $50 \mu \mathrm{m}$ and depth $15 \mu \mathrm{m}$ ) and Ti6Al4V (diameter $150 \mu \mathrm{m}$ and depth $40 \mu \mathrm{m}$ ) samples were subjected to wear testing, obtaining COF reductions of approximately $65 \%[14,31]$. In contrast, there are publications where the use of dimples is not favourable, even obtaining a COF difference of $\sim$ $9 \%$, when Ti6Al4V samples were textured with dimple arrays with $260 \mu \mathrm{m}$ diameter [37]. The greatest difference between the works where a COF reduction was obtained and the one where the COF difference increased is the contact pressure that was applied in the tribological tests, since in those that had a positive difference, pressure ranges of 0.05 $0.239 \mathrm{MPa}$ were used., while in the work of Qin et al., a pressure of approximately $984 \mathrm{MPa}$ was applied.

\section{CONCLUSIONS}

A review of the literature related to the use of surface texturing to reduce the wear of materials used for the manufacture of joint prostheses was carried out, emphasizing the impact that different texturing techniques, characteristics of cavities, and texturing patterns geometries had in the COF reduction in tribological tests. The number of publications related to the use of surface texturing for biomedical applications has increased considerably in the last 15 years, so it can be assumed that the scientific community has a rising interest in studying the effects that these selective material removal techniques have on the tribological behaviour of the friction pairs that make up joint prostheses.

After analysing different publications in this review, it can be concluded that LST is the most widely used technique in research that seeks to reduce wear in biotribology applications through surface texturing techniques. One of the main advantages of using LST is its adaptability, different geometries such as dimples, squares, triangles, grooves, and crosshatch can be fabricated. It is important to mention that if strict control of the input parameters of surface texturing is achieved, patterns with very complex geometries can be obtained, as in the work of Zhang et al., where CoCrMo samples were textured with petaloid geometries, it should be emphasized that in addition to using a complex pattern, a 30\% COF reduction was obtained in tribological tests, when compared to untextured CoCrMo samples [12]. Different texturing patterns such as linear grooves, squares and crosshatch have been used obtaining COF reductions of $\sim 80 \%[24,32,38]$; however, there is a marked preference in the use of dimples, which can be attributed to their easy manufacture and favourable results in tribological tests.

\section{REFERENCES}

1. García E. 2011 Evaluación de la estancia hospitalaria en prótesis de cadera. Alcalá Henares Univ Alcalá Henares.

2. Sawano H, Warisawa S, Ishihara S. 2009 Study on long life of artificial joints by investigating optimal sliding surface geometry for improvement in wear resistance. Precis Eng 33 492-498

https://doi.org/10.1016/j.precisioneng 2009.01.005.

3. Agarwal S. 2004 Osteolysis - Basic science, incidence and diagnosis. Curr Orthop 18 220-231 https://doi.org/10.1016/j.cuor.2004.03.002.

4. Kosukegawa I, Nagoya S, Kaya M, Sasaki K, Sasaki M, Yamashita T. 2011 Revision Total Hip Arthroplasty Due to Pain From Hypersensitivity to CobaltChromium in Total Hip Arthroplasty. $J$ Arthroplasty 26 978.e1-978.e3.

https://doi.org/10.1016/j.arth.2010.09.003.

5. Arirajan KA, Chockalingam K, Vignesh C. 2018 Selection of contact bearing couple materials for hip prosthesis using finite element analysis under static conditions. AIP Conf Proc 1943. 
https://doi.org/10.1063/1.5029589.

6. Hernández-Rodríguez MAL, Mercado-Solís RD, Pérez-Unzueta AJ, Martinez-Delgado DI, CantúSifuentes M. 2005 Wear of cast metal-metal pairs for total replacement hip prostheses. Wear 259 958-963 https://doi.org/10.1016/j.wear.2005.02.080.

7. Atienza C, Comín M, Peris JL, Mollá F. 2002 Evaluación del desgaste en prótesis articulares mediante simuladores. Rev Biomecánica 37 7-9.

8. Hu T, Hu L, Ding Q. 2012 The effect of laser surface texturing on the tribological behavior of Ti6Al-4V. Proc Inst Mech Eng Part J J Eng Tribol 226 854-863 https://doi.org/10.1177/1350650112450801.

9. Etsion I. 2005 State of the art in laser surface texturing. J Tribol 127 248-253

https://doi.org/10.1115/1.1828070.

10. Kumari R, Scharnweber T, Pfleging W, Besser H, Majumdar JD. 2015 Laser surface textured titanium alloy (Ti-6Al-4V) - Part II - Studies on biocompatibility. Appl Surf Sci $\mathbf{3 5 7}$ 750-758 https://doi.org/10.1016/j.apsusc.2015.08.255.

11. Liu X, Zhao G, Qiu J. 2018 Effect of laser surface texturing on tribological properties of polyimide composites in the application of traveling wave rotary ultrasonic motor. Ind Lubr Tribol 70 569-577 https://doi.org/10.1108/ILT-06-2016-0130.

12. Zhang H, Qin LG, Hua M, Dong G, Chin KS. 2015 A tribological study of the petaloid surface texturing for $\mathrm{Co}-\mathrm{Cr}-\mathrm{Mo}$ alloy artificial joints. Appl Surf Sci 332 557-564

https://doi.org/https://doi.org/10.1016/j.apsusc.2015.0 1.215 .

13. Ito H, Kaneda K, Yuhta T, Nishimura I, Yasuda K, Matsuno T. 2000 Reduction of polyethylene wear by concave dimples on the frictional surface in artificial hip joints. J Arthroplasty 15 332-338 https://doi.org/10.1016/S0883-5403(00)90670-3.

14. Zhang B, Huang W, Wang J, Wang X. 2013 Comparison of the effects of surface texture on the surfaces of steel and UHMWPE Tribol Int $\mathbf{6 5} 138$ 145 https://doi.org/10.1016/j.triboint. 2013.01.004.

15. Riveiro A, Maçon ALB, del Val J, Comesaña R, Pou J. 2018 Laser surface texturing of polymers for biomedical applications Front Phys 5 https://doi.org/10.3389/fphy.2018.00016.

16. Ortega-Ramos IA, Alvarez-Vera M, AcevedoDávila JL, Hdz-García HM, Muñoz-Arroyo R. 2019 Effect of the surface texturing treatment with $\mathrm{Nd}$ : YAG laser on the wear resistance of $\mathrm{CoCr}$ alloy $M R S$ Adv 4 3031-3039

https://doi.org/10.1557/adv.2019.397.

17. Taha-Tijerina JJ, Garza GT, Maldonado-Cortés D. 2018 Evaluation of parameters for application of Laser Surface Texturing (LST) in tooling for the sheet-metal forming process. Ind Lubr Tribol 70 620$627 \mathrm{https}: / /$ doi.org/10.1108/ILT-07-2017-0194.

18. Won SJ, Kim HS. 2019 Effects of laser parameters on morphological change and surface properties of aluminum alloy in masked laser surface texturing $J$ Manuf Process 48 260-269 https://doi.org/10.1016/j.jmapro.2019.10.034.

19. Dong Y, Svoboda P, Vrbka M, Kostal D, Urban F, Cizek J, et al. 2016 Towards near-permanent CoCrMo prosthesis surface by combining microtexturing and low temperature plasma carburising $J$ Mech Behav Biomed Mater 55 215-227 https://doi.org/10.1016/j.jmbbm. 2015.10.023.

20. Pratap T, Patra K. 2018 Mechanical microtexturing of Ti-6Al-4V surfaces for improved wettability and bio-tribological performances. Surf Coatings Technol 349 71-81.

https://doi.org/10.1016/j.surfcoat.2018.05.056.

21. Ghosh S, Choudhury D, Roy T, Bin Mamat A, Masjuki HH, Pingguan-Murphy B. 2015 Tribological investigation of diamond-like carbon coated microdimpled surface under bovine serum and osteoarthritis oriented synovial fluid Sci Technol Adv Mater 16 1-11. https://doi.org/10.1088/14686996/16/3/035002.

22. Roy T, Choudhury D, Bin Mamat A, PingguanMurphy B. 2014 Fabrication and characterization of micro-dimple array on $\mathrm{Al} 2 \mathrm{O} 3$ surfaces by using a micro-tooling Ceram Int $40 \quad 2381-2388$ https://doi.org/10.1016/j.ceramint.2013.08.009.

23. Xing Y, Deng J, Wu Z, Wu F. 2017 High friction and low wear properties of laser-textured ceramic surface under dry friction Opt Laser Technol 9324 32. https://doi.org/10.1016/j.optlastec.2017.01.032.

24. Xing Y, Deng J, Wang X, Meng R. 2015 Effect of laser surface textures combined with multi-solid lubricant coatings on the tribological properties of A12O3/TiC ceramic Wear 342-343 1-12 https://doi.org/10.1016/j.wear.2015.08.002.

25. Qin L, Lin P, Zhang Y, Dong G, Zeng Q. 2013 Influence of surface wettability on the tribological properties of laser textured Co-Cr-Mo alloy in aqueous bovine serum albumin solution Appl Surf Sci $26879-86$

https://doi.org/10.1016/j.apsusc.2012.12.003.

26. Ren S, Huang J, Cui M, Pu J, Wang L. 2017 Improved adaptability of polyaryl-ether-ether-ketone with texture pattern and graphite-like carbon film for bio-tribological applications. Appl Surf Sci 400 24-37 https://doi.org/10.1016/j.apsusc.2016.12.159.

27. Dufils J, Faverjon F, Héau C, Donnet C, Benayoun S, Valette S. 2017 Combination of laser surface texturing and DLC coating on PEEK for enhanced tribological properties Surf Coatings Technol 329 29-41

https://doi.org/10.1016/j.surfcoat.2017.09.028.

28. Tiainen L, Abreu P, Buciumeanu M, Silva F, Gasik M, Serna Guerrero R, et al. 2019 Novel laser surface texturing for improved primary stability of titanium implants $J$ Mech Behav Biomed Mater 98 
26-39 https://doi.org/10.1016/j.jmbbm.2019.04.052. 29. Sadeghi M, Kharaziha M, Salimijazi HR, Tabesh E. 2019 Role of micro-dimple array geometry on the biological and tribological performance of Ti6Al4V for biomedical applications Surf Coatings Technol 362 282-292

https://doi.org/10.1016/j.surfcoat.2019.01.113.

30. Wu Z, Xing Y, Huang P, Liu L. 2017 Tribological properties of dimple-textured titanium alloys under dry sliding contact Surf Coatings Technol 309 21-28 https://doi.org/10.1016/j. surfcoat.2016.11.045.

31. Hu T, Hu L, Ding Q. 2012 Effective solution for the tribological problems of Ti-6Al-4V: Combination of laser surface texturing and solid lubricant film Surf Coatings Technol 206 5060-5066

https://doi.org/10.1016/j.surfcoat.2012.06.014.

32. Singh A, Patel DS, Ramkumar J, Balani K. 2018 Single step laser surface texturing for enhancing contact angle and tribological properties Int $J A d v$ Manuf Technol 100 1253-1267 https://doi.org/10.1007/s00170-018-1579-8.

33. Kümmel D, Hamann-Schroer M, Hetzner $H$, Schneider J. 2019 Tribological behavior of nanosecond-laser surface textured Ti6Al4V Wear 422-423 261-268.

https://doi.org/ 10.1016/j.wear.2019.01.079.

34. Wang C, Li Z, Zhao H, Zhang G, Ren T, Zhang Y. 2020 Enhanced anticorrosion and antiwear properties of Ti-6Al-4V alloys with laser texture and graphene oxide coatings Tribol Int $\mathbf{1 5 2} 106475$ https://doi.org/10.1016/j.triboint.2020.106475.

35. He D, Zheng S, Pu J, Zhang G, Hu L. 2015 Improving tribological properties of titanium alloys by combining laser surface texturing and diamondlike carbon film Tribol Int 82 20-27. https://doi.org/10.1016/j.triboint.2014.09.017.

36. Kashyap V, Ramkumar P. 2019 Feasibility study of micro-groove cross hatched surface texturing on Ti6Al4V for improved biotribological performance in metal-on-polymer hip implant Tribol - Mater Surfaces Interfaces 13 150-160. https://doi.org/10.1080/17515831.2019.1606582.

37. Qin Y, Xiong D, Li J. 2015 Tribological properties of laser surface textured and plasma electrolytic oxidation duplex-treated Ti6Al4V alloy deposited with MoS2 film Surf Coatings Technol 269 266-272

https://doi.org/10.1016/j.surfcoat.2014.12.003.

38. Arenas MA, Ahuir-Torres JI, García I, Carvajal H, de Damborenea J. 2018 Tribological behaviour of laser textured Ti6Al4V alloy coated with MoS2 and graphene Tribol Int $\mathbf{1 2 8}$ 240-247 https://doi.org/10.1016/j.triboint.2018.07.031.

39. Hussain M, Sufyan M, Abbas N, Ahmad H, Joyia FM, Noman M, et al. 2019 Influence of laser processing conditions for texturing on ultra-high-molecular-weightpolyethylene (UHMWPE) surface. Case Stud Therm Eng 14100491

https://doi.org/10.1016/j.csite.2019.100491.

40. Dai FZ, Geng J, Tan WS, Ren XD, Lu JZ, Huang S. 2018 Friction and wear on laser textured Ti6Al4V surface subjected to laser shock peening with contacting foil Opt Laser Technol 103 142-150 https://doi.org/10.1016/j.optlastec.2017.12.044.

41. Roy T, Choudhury D, Ghosh S, Mamat A Bin, Pingguan-Murphy B. 2014 Improved friction and wear performance of micro dimpled ceramic-onceramic interface for hip joint arthroplasty Ceram Int 41 681-690

https://doi.org/10.1016/j.ceramint.2014.08.123.

42. Pratap T, Patra K. 2020 Tribological performances of symmetrically micro-textured Ti-6Al-4V alloy for hip joint Int $J$ Mech Sci 182105736. https://doi.org/10.1016/j.ijmecsci.2020.105736.

43. Kustandi TS, Choo JH, Low HY, Sinha SK. 2009 Texturing of UHMWPE surface via NIL for low friction and wear properties $J$ Phys D Appl Phys $\mathbf{4 3}$ https://doi.org/10.1088/0022-3727/43/1/015301.

44. Jones K, Schmid SR. 2016 Experimental Investigation of Laser Texturing and its Effect on Friction and Lubrication Procedia Manuf 5 568-577. https://doi.org/10.1016/j.promfg.2016.08.047.

45. Hadley M, Hardaker C, Isaac G, Fisher J. 2018 Wear of different materials for total hip replacement under adverse stop-dwell-start in vitro wear simulation conditions Proc Inst Mech Eng Part $H J$ Eng Med 232 1261-1270

https://doi.org/10.1177/0954411918813385.

Received: March 22, 2021 / Accepted: December 20, 2021 / Paper available online: December 25, 2021 (C) International Journal of Modern Manufacturing Technologies 